\title{
The chemical analysis and replication of polydimethylsiloxane by-products located within electrical trees
}

DOI:

10.1109/CEIDP.2012.6378848

Link to publication record in Manchester Research Explorer

Citation for published version (APA):

Freebody, N. A., Vaughan, A. S., Lunt, P. J. B., Flavell, W. R., \& Wincott, P. L. (2012). The chemical analysis and replication of polydimethylsiloxane by-products located within electrical trees. In Annual Report - Conference on Electrical Insulation and Dielectric Phenomena, CEIDP/Annu. Rep. Conf. Electr. Insul. Dielectr. Phenom. CEIDP (pp. 585-588). IEEE. https://doi.org/10.1109/CEIDP.2012.6378848

Published in:

Annual Report - Conference on Electrical Insulation and Dielectric Phenomena, CEIDP|Annu. Rep. Conf. Electr. Insul. Dielectr. Phenom. CEIDP

\section{Citing this paper}

Please note that where the full-text provided on Manchester Research Explorer is the Author Accepted Manuscript or Proof version this may differ from the final Published version. If citing, it is advised that you check and use the publisher's definitive version.

\section{General rights}

Copyright and moral rights for the publications made accessible in the Research Explorer are retained by the authors and/or other copyright owners and it is a condition of accessing publications that users recognise and abide by the legal requirements associated with these rights.

\section{Takedown policy}

If you believe that this document breaches copyright please refer to the University of Manchester's Takedown Procedures [http://man.ac.uk/04Y6Bo] or contact uml.scholarlycommunications@manchester.ac.uk providing relevant details, so we can investigate your claim.

\section{OPEN ACCESS}




\section{The Chemical Analysis and Replication of Polydimethylsiloxane By-Products located within Electrical Trees}

\author{
N.A. Freebody*, A.S. Vaughan \\ School of Electronics and Computer \\ Science \\ University of Southampton \\ Southampton, SO17 1BJ, UK
}

\author{
P. J. B. Lunt, W. R. Flavell \\ School of Physics, Astronomy and Photon \\ Science Institute \\ University of Manchester \\ Manchester, M13 9PL, UK
}

\author{
P. L. Wincott \\ School of Earth, Atmospheric and \\ Environmental Science \\ University of Manchester \\ Manchester, M13 9PL, UK
}

\begin{abstract}
We present a spectroscopic study of electrical trees grown in polydimethylesiloxane (PDMS) rubber. Electrical trees were grown at a range of voltages and allowed to propagate throughout the material. Breakdown and tree channels were exposed using cryogenic microtoming. Raman microprobe spectroscopy (RMS), Fourier Transform Infrared (FTIR), and X-ray Photoelectron Spectroscopy (XPS) were applied in order to obtain a detailed spectroscopic analysis of electrical treeing and breakdown in PDMS rubber.

For comparison, a selection of liquid systems including PDMS oil, dodecylbenzene (DDB) and dodecane (DD) were subjected to ageing via electrical discharges between two electrodes. The debris subsequently formed was subjected to spectroscopic analysis as before. Results are discussed in comparison to previously published results involving electrical treeing and corona discharge experiments in polyethylene (PE) and PDMS rubber.
\end{abstract}

\section{INTRODUCTION}

The formation of electrical trees in polymers can lead to catastrophic electrical breakdown and failure of the material in its ability to act as an insulator. The development and growth of electrical trees involves the chemical conversion of polymers into volatile fragments due to the transfer of energy from the electric field [1]. In order to understand the processes involved in the formation and propagation of electrical trees in polymers, it is also necessary to understand the chemical processes involved within the polymer during treeing and the development of these volatile by-products. Due to the small quantities of the by-products produced in electrical treeing however, this can be challenging. Previously published papers [2] have suggested the application of Raman microprobe spectroscopy (RMS) for this purpose as it has a potential lateral resolution of $\sim 1 \mu \mathrm{m}[3]$ and is therefore able to characterise the exact chemical composition of a material. This method however is not without its flaws and is often used in conjunction with Fourier Transform Infra Red (FTIR) which although does not have the same resolution can help to identify the chemical makeup of the sample in question. Xray Photoelectron Spectroscopy (XPS) can also enable the volatile by-products at the polymer surface to be analysed and identified as it is a quantitative spectroscopic technique that can measure the composition, chemical and electronic state of the elements that comprise the surface few $\mathrm{nm}$ of the material.

Some papers have suggested that in order to understand the formation of electrical trees in polymeric systems, the same volatile fragments present in electrical treeing in bulk need to be generated using alternative methods $[4,5]$. By doing this, a wider range of spectroscopic techniques can be applied and the exact processes involved in electrical treeing investigated. It has been suggested that a potential method for achieving this is to corona age a polymer in an inert atmosphere and collect the deposits formed on the needle electrode [5]. The problem with using this method is that although it accurately replicates the chemistry of electrical trees, a large amount of time is needed to generate enough debris for analysis.

This study takes a systematic approach to applying RMS, FTIR and XPS to electrical trees and breakdown channels grown in PDMS. This not only allows a comparison of the methods involved to be made but a deeper understanding of the by-products formed in electrically-aged PDMS to be achieved. We also present a novel approach to the bulk generation of these by-products where liquid systems of a similar chemistry to solid polymers are aged via spark ageing, producing large quantities of debris for analysis.

\section{EXPERIMENTAL}

The solid PDMS samples in this study were all made from the Dow Corning Sylgard 184 Silicone Elastomer kit. This kit contains the base compound and a curing agent. In order to make the samples the 2 compounds were mixed at a ratio of $10: 1$, degassed and cured in a mould at $100{ }^{\circ} \mathrm{C}$. Samples were then cut to size $\left(6 \times 10 \times 15 \mathrm{~mm}^{3}\right)$ and a needle was slowly inserted in order to grow electrical trees.

In addition to electrical treeing, 3 liquid systems, dodecane (DD), dodecylbenzene (DDB) and PDMS, were subjected to electrical ageing via a spark generator. In each case the spark generator (with a spark gap of $0.3 \mathrm{~mm}$ ) was immersed into 20 $\mathrm{ml}$ of the fluid and was set to a spark rate of approximately 1 spark per second for 16 hours. The energy and discharge duration of the sparks was controlled by the values of a capacitor and resistor set to 4 and $0.25 \mathrm{nF}$ for the capacitor and $1.25 \mathrm{M} \Omega$ for the resistor. Following ageing the debris was 
separated from the remaining liquid using a centrifuge and acetone (in the case of DD, hexane was used to clean the debris due to its similar chemical nature to DD) such that a fine powder was produced.

Analysis of all samples was performed using a Renishaw RM1000 Raman microprobe system including a Renishaw

NIR 780TF diode laser (wavelength $780 \mathrm{~nm}$ ) with a maximum output power of $25 \mathrm{~mW}$ and a x 50 objective lens. All spectra were acquired using 25 consecutive $10 \mathrm{~s}$ extended scans between $3200 \mathrm{~cm}^{-1}$ and $100 \mathrm{~cm}^{-1}$ with the laser set to $25 \%$ power to reduce sample damage.

FTIR spectra were obtained using a Perkin Elmer Spectrum GX instrument coupled with an AutoIMAGE FTIR microscope and a liquid-nitrogen-cooled MCT high-sensitivity photo-detector. Samples were mounted upon a gold-coated slide and analysed in reflection mode using an accumulation of 30 scans of $1 \mathrm{~s}$ each to reduce the signal to noise ratio and a sampling area of $100 \mu \mathrm{m}^{2}$ over a range of $500-4000 \mathrm{~cm}^{-1}$.

A Kratos AXIS Ultra spectrometer using a monochromated Al X-ray source at $1486.6 \mathrm{eV}$ was used to analyse the samples via XPS. Line scans of the samples were taken using the 110 $\mu \mathrm{m}$ aperture with a $300 \mu \mathrm{m}$ separation between scans. In all cases, charge compensation using a magnetic immersion lens was necessary.

\section{RESULTS AND DISCUSSION}

\section{A. Electrical treeing in PDMS}

Electrical trees were grown at $1 \mathrm{kV}$ intervals between $10 \mathrm{kV}$ and $15 \mathrm{kV}$ and were allowed to propagate between the two electrodes such that complete breakdown occurred. For comparison, one electrical tree was grown at $15 \mathrm{kV}$ but the electrical field was terminated prior to breakdown. The resulting tree and breakdown channels were then exposed via cryo-microtoming. Raman and FTIR scans were taken at regular intervals along a perpendicular axis across the exposed tree channels as shown in figure 1. By doing this the changes in chemical makeup of the tree/breakdown channels with respect to position can be seen.

Figure 2 shows the Raman spectra for a breakdown channel and an electrical tree grown at $15 \mathrm{kV}$. Both of these show typical results. The spectra have all been displaced by an arbitrary amount in the y axis to aid viewing. In the spectra for the breakdown channel it can be seen that away from the

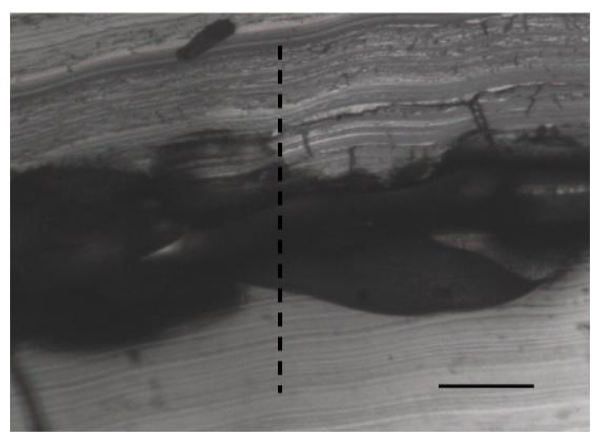

Fig. 1. Optical micrograph of an electrical breakdown channel in PDMS. Dashed line indicates axis along which spectroscopic scans were obtained. channel a typical spectrum for PDMS can be seen with peaks at 448, 687 and $787 \mathrm{~cm}^{-1}$ which are related to the Si-O-Si stretch, $\mathrm{Si}-\mathrm{CH}_{3}$ rotation and $\mathrm{Si}-\mathrm{C}$ stretching modes respectively. In spectra obtained from the inside of the breakdown channel, two broad bands relating to the D and $G$ bands of $\mathrm{sp}^{2}$ hybridised carbon can be seen at 1250 and 1550 $\mathrm{cm}^{-1}$. This indicates that the energies involved in breakdown in PDMS are sufficient to break the bonds of the $\mathrm{CH}$ side groups in the PDMS which then form polycyclic aromatic hydrocarbons (PAHs) and graphite [6]. The spectra relating to PAHs can be seen throughout the breakdown channel but seems to be of greatest intensity at the edges of the channel. In all of the spectra in figure $2 \mathrm{a}$ ), one of the peaks related to the unaged PDMS is also present. For the breakdown channels generated at different voltages the same chemical signatures are present and an increase in voltage does not appear to affect the quantity of the PAHs present only the time taken for the sample to breakdown.

In contrast with this, the Raman spectra of the electrical tree channel that was terminated before breakdown occurred does not contain any evidence of the formation of PAHs. In these spectra the chemical matrix of PDMS appears to have
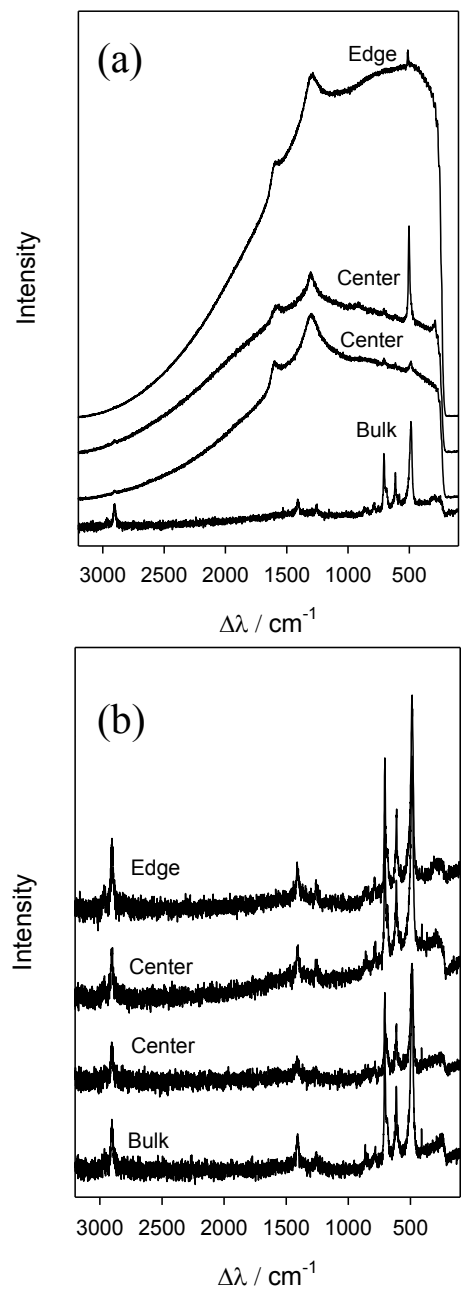

Fig. 2. Raman spectra taken at regular intervals across a) a breakdown channel and b) an electrical tree channel in PDMS 
remained unchanged. This suggests that although physical damage occurs during electrical treeing in PDMS, the energies involved are insufficient to break any of the chemical bonds within the matrix. These results vary little when the electrical trees are grown at different voltages. An increase in voltage creates an increase in fractal dimension of the tree in question but does not appear to affect the internal chemistry of the tree.

Figures 3 a) and b) show typical FTIR spectra of trees and breakdown channels grown at different voltages. The spectra in these figures have been normalized and displaced by an arbitrary amount in the y axis to aid viewing. In figure 3 a), which corresponds to a breakdown channel grown at $15 \mathrm{kV}$, it can be clearly seen that there are large peaks located at approximately 1018,1085 , and $1257 \mathrm{~cm}^{-1}$ (which are related to the Si-O stretching mode of PDMS) present in one of the breakdown channel spectra. In addition, peaks located between 1797 and $2150 \mathrm{~cm}^{-1}$ are observed, which are assigned to the carbonyl groups and $\mathrm{C}-\mathrm{H}$ bonds. The presence of these peaks reinforce the Raman data and together, the data show that within the breakdown channel there is an increase in carbon-containing species relating to PAHs originating from the side groups of the PDMS bulk. It is worth noting that
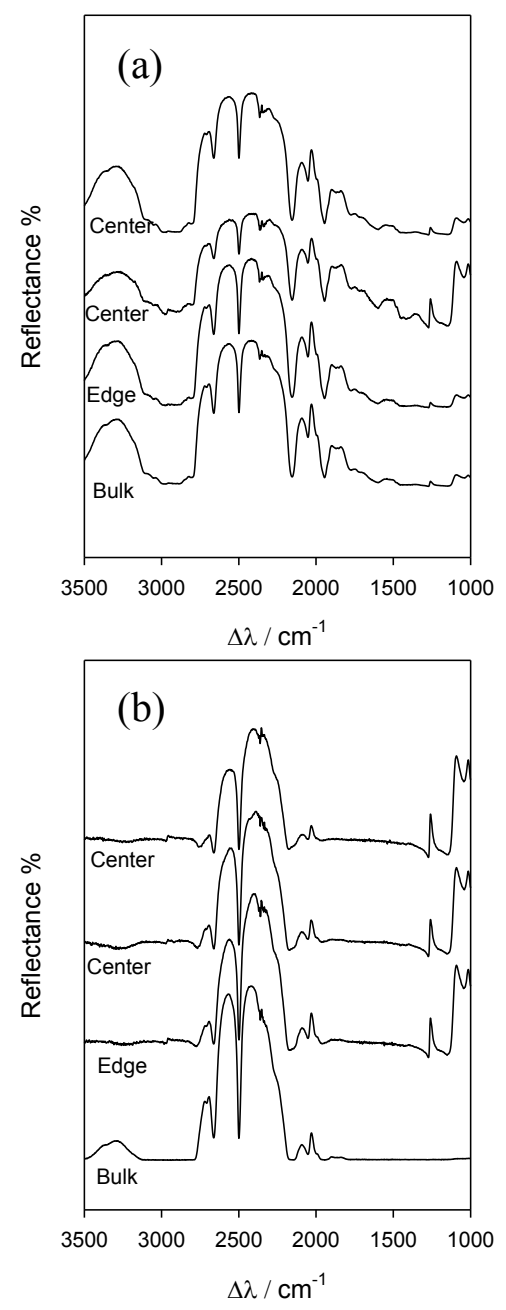

Fig. 3. FTIR spectra taken at regular intervals across a) a breakdown channel and b) an electrical tree channel in PDMS evidence of the bulk matrix can be seen in the channel and the signal from the channel can be seen in the bulk spectra. This is due to the poor lateral resolution of the FTIR which can only sample areas of $100 \mu \mathrm{m}^{2}$ and larger.

In the FTIR spectra obtained from a tree channel grown at the same voltage (figure $3 \mathrm{~b}$ ) the peaks at 1018, 1085, and $1257 \mathrm{~cm}^{-1}$ are also present. In these spectra, peaks located between $1950 \mathrm{~cm}^{-1}$ and $2780 \mathrm{~cm}^{-1}$ can also be seen which are assigned to the chemical bonds within the polymer matrix as they are present in both the aged and un-aged scans. It can be seen in these spectra that there is little chemical difference detectable in the FTIR spectra between PDMS and the tree channels. Although this supports the Raman data for the same channels, the poor lateral resolution of the FTIR spectrometer cannot be ruled out as a possible cause.

XPS analysis was applied to several of the breakdown channels and the tree channel grown at $15 \mathrm{kV}$. The lateral resolution of XPS (around $10 \mu \mathrm{m}$ ) proved insufficient to obtain data from the treeing channels. Figure 4 shows data obtained from a breakdown channel obtained at $14 \mathrm{kV}$. Figure 4 a) shows an image denoting the concentration of various elements across the breakdown channel obtained by measuring the photoelectron peak area for each element at each pixel. Figure 4 b) shows a graph indicating the concentration of carbon, oxygen and silicon around the breakdown channel. In both of these figures it is clear that there is evidence that there is an increased concentration of carbon around the edges of the breakdown channel and a decrease in silicon and oxygen concentration in the same

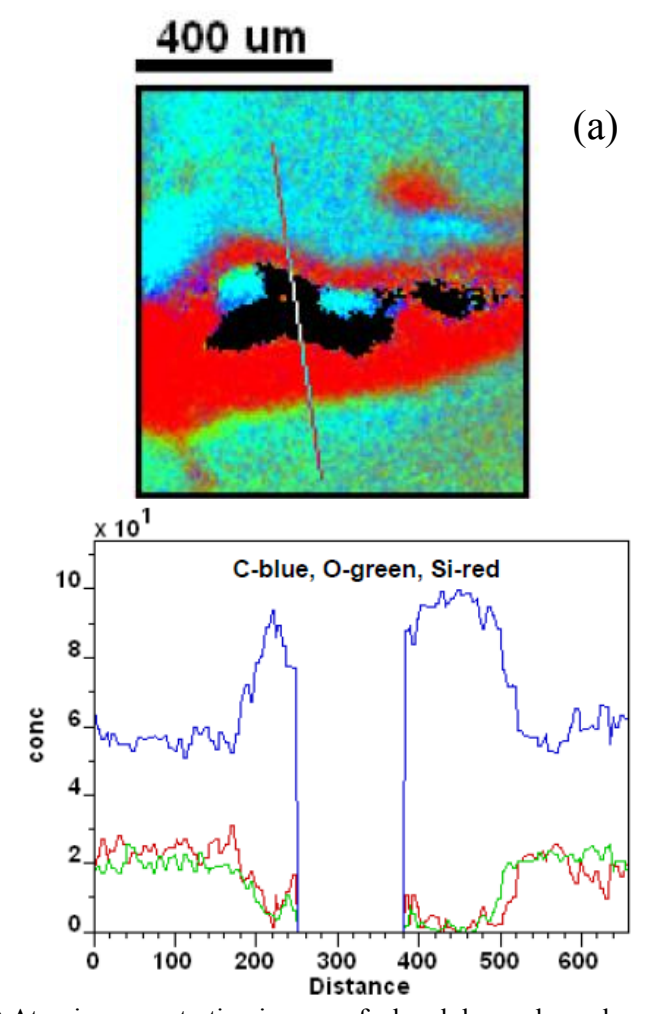

(b)

Fig. 4. a) Atomic concentration images of a breakdown channel grown at 14 $\mathrm{kV}$ where $\mathrm{x}$ - carbon, $\mathrm{x}$ - oxygen and $\mathrm{x}$ - silicon, b) graph denoting the concentration of elements along the line indicated in a) 


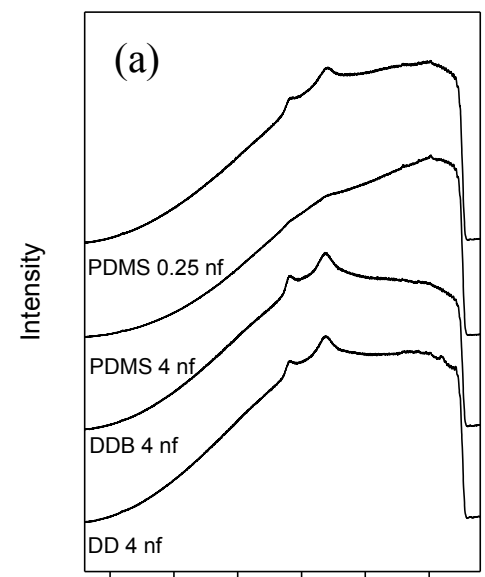

30002500200015001000500 $\Delta \lambda / \mathrm{cm}^{-1}$

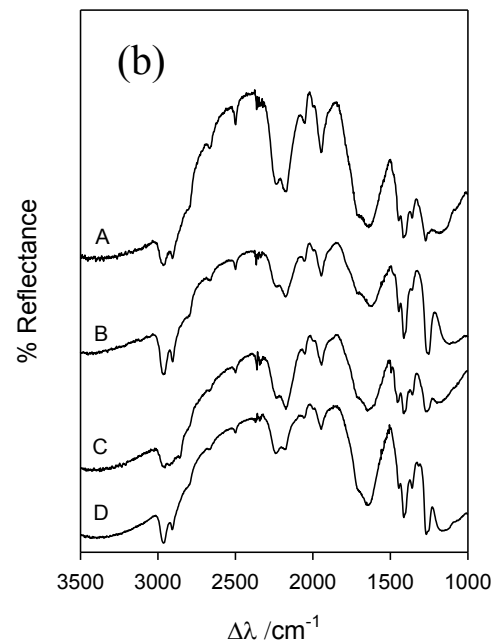

Fig. 5. Average Raman (a) and FTIR (b) spectra of the various liquid systems aged via spark ageing. A - PDMS (0.25 nF), B - PDMS (4 nF), C - DDB (4 $\mathrm{nF})$ and $\mathrm{D}-\mathrm{DD}(4 \mathrm{nF})$

region. More detailed analysis of the local spectra (not shown) revealed some oxidation of the carbon and silicon and evidence of graphitic carbon. These results are consistent with the RMS and FTIR data also presented in this paper.

\section{B. Spark ageing of liquids}

In an attempt to replicate in bulk the chemistry involved in electrical treeing in polymers, various liquid systems were subjected to spark ageing. DD was chosen due to its simple chemical makeup which constitutes a similar chemistry to polyethylene. DDB was chosen due to its organic backbone and highly aromatic structure thus making it a good candidate to simulate polymers such as epoxy resin. Finally a liquid form of PDMS was chosen to exactly replicate the chemistry of the treeing samples in this paper.

Figure 5 shows the average Raman and FTIR data obtained from each of the spark-generated powders generated from 10 scans from each powder. From the Raman spectra in figure 5 a), it can be seen that all of the powders obtained yield a similar chemical signature with the $D$ and $G$ bands of $s^{2}$ hybridized carbon clearly seen in all spectra. The same chemical signatures can be seen in the spectra obtained from the breakdown channels in PDMS and have been identified in previous publications in electrical treeing studies of other polymeric systems.

The FTIR spectra in figure $5 \mathrm{~b}$ ) have all been normalised to the peak found at $2245 \mathrm{~cm}^{-1}$. The spectra were then all displaced by arbitrary amounts to aid viewing. It can be seen that between the different liquid systems the same peaks (as identified in the previous section) are present but with different reflectance ratios indicating different quantities of these by-products.

The quantity of powder produced by spark ageing DD and DDB was insufficient to produce a clear signal in XPS and a complex method of subtracting the signal from that of the underlying substrate was applied. Nevertheless, it was clear that the powders obtained from DD and DDB contain a large amount of C-O- bonds compared with the unaged oil. The powder from PDMS also showed some oxidised components. In these samples however, there was a strong component from clean PDMS possibly due to residual PDMS on the powder.

We conclude that although this method is still in its infancy and much work needs to be done to apply it to other systems to confirm the results presented here, spark ageing is an effective way of reproducing the chemistry involved in electrical treeing within polymeric insulators.

\section{CONCLUSIONS}

In both the electrical breakdown channels and liquid systems, our results reveal similar chemical by-products of breakdown, namely $\mathrm{sp}^{2}$ hybridised carbon and small amounts of oxidised carbon and silicon (in the case of PDMS) species. Only the quantity and not the chemical nature of these by-products are affected by the breakdown voltage. We find that it is possible to use a liquid system of a suitable chemical structure to recreate in bulk the chemical by-products associated with electrical trees in various polymers thus enabling a more indepth analysis of the formation of electrical trees to be made.

\section{REFERENCES}

[1] O. P. Poznansky, "Bush region in the propagation of electrical degradation in polymers". Computational and Theoretical Polymer Science, 2001. 11(1): p. 81-82.

[2] A. S. Vaughan, et al., "On the structure and chemistry of electrical trees in polyethylene" Journal of Physics D-Applied Physics, 2006. 39(5): p. 962-978.

[3] R. Tabaksblat, R. J. Meier, and B. J. Kip, "Confocal Raman Microsocpy - Theory and application to thin ploymer samples" Applied Spectroscopy, 1992. 46(1): p. 60-68.

[4] X. S. Liu, A.S. Vaughan, and G. Chen, "A Raman spectroscopic study of bulk and surface ageing phenomena in polyethylene". 2003 Annual Report Conference on Electrical Insulation and Dielectric Phenomena, 2003: p. 145-148.

[5] N. A. Freebody, and A.S. Vaughan, "Surface ageing of dielectric materials in a controlled atmosphere: A Raman microprobe study", 2010 IEEE Conference on Electrical Insulation and Dielectric Phenomena (CEIDP 2010), 2010.

[6] G. Mazzanti, and G. C. Montanari, "Electrical aging and life models: the role of space charge." Dielectrics and Electrical Insulation, IEEE Transactions on, 2005. 12(5): p. 876-890 